\title{
Positive Analysis of Potential in China's Cotton Import
}

$$
\text { Chun-Xiang LIU }{ }^{1, a} \text {, Rong CHEN }{ }^{1, b, *}
$$

${ }^{1}$ Finance and Trade School, Ningbo DaHongYing University, Ningbo, Zhejiang 315175, China

a171653939@qq.com, b710622503@qq.com

Keywords: Improved gravity model, Cotton export price, limport development potential, Multivariate regression analysis.

\begin{abstract}
Since 2003, China has been the largest importer of cotton in the world. Generally, China's cotton import has relatively high market centralization at present with the cotton imported from top three trading partners taking up 74.94\% of the total import of cotton. This paper constructed an improved gravity model of trade and analyzed the development potential of China's cotton import by utilizing the panel data during 1992-2016 of top forty trading partners. Results of the empirical study show that the cotton imported to China from fourteen countries including Switzerland, Nigeria, Bengal, Indonesia, Turkey and Australia is at the stage of excessive import"; the cotton imported to China from eleven countries including Cameroon, Egypt, Togo, Chad, Mali and India is at the stage of "import saturation", so there is limited space for the import of cotton from those countries; the cotton imported to China from fifteen countries including Cote d'Ivoire, Zambia, Malaysia, Tajikistan and Brazil is at the stage of "insufficient import". Besides, China shall preferentially import cotton from Turkmenistan, Iran and Malaysia which offer relatively lower export price and increase imports from Brazil and Greece these two major cotton producers and exporters.
\end{abstract}

\section{Introduction}

China's cotton imports fluctuated quite a bit after 2003. It grew as a whole from 2003 to 2012 and reached its peak in 2012 with the imports of 12.001 billion dollars. The amount declined then and fell down to 1.774 billion dollars in 2016.

Table 1 Five Trading Partners of China’s Cotton Import in 2016 (1 million dollars, \%)

\begin{tabular}{|c|c|c|}
\hline Import source market & Cotton import price & Proportion of China's total cotton imports \\
\hline America & 513.68 & 29.09 \\
\hline Australia & 382.78 & 22.07 \\
\hline India & 239.08 & 13.18 \\
\hline Uzbekistan & 179.49 & 10.28 \\
\hline Brazil & 129.78 & 7.14 \\
\hline Other partners & 333.46 & 18.24 \\
\hline
\end{tabular}

China's cotton import source countries' concentration is really high. After 1999, the annual average import quantity of top 5 source countries of China's cotton import accounts for about $80 \%$ of the total import quantity of that year and it reached 89.53\% in 2014 and remained 81\% in 2016 (see Table 1 for details). America, Australia and Uzbekistan have been China's cotton importing countries and have ranked top five in China's cotton import since 1999. In recent years, China has increased its import of cotton from India. In 2016, the amount of cotton imported from India exceeded that from Uzbekistan and reached 239.08 million dollars.

The over-reliance of China's cotton import on specific markets is not beneficial to steady supply of cotton, so China sorely needs to realize diversification of cotton import markets. This paper will construct an improved gravity model and empirically measure the development potential of China's cotton import from all trading partners. 


\section{Construction of the Improved Trade Gravity Model of the Cotton Import of China}

According to the actual situations of the import trade of the cotton industry of our country and on the basis of referring to the relative documents, this paper is to build the gravity model of the improved trade from six elements including the economic aggregate of China, the cotton yield of the importing country (region) of origin, the export price of the cotton of the importing country (region) of origin, the geographical distance of the importing country (region) of origin with our country, the population of our country and the harvested area of cotton of our country.

1. The economic aggregate of China. The economic aggregate of our country has reflected the import demand of our country for the cotton, as the larger the economic scale is, the higher the import potential of a country is, which raises assumption 1: the economic aggregate GDP of China is positively correlated with the import scale of China on cotton.

2. The cotton yield of the importing country (region) of origin. The cotton yield of an importing country (region) of origin can represent its supply capacity on cotton. The larger the cotton yield is, the higher its export capability is. Which raises assumption 2: the cotton yield of the importing country (region) of origin is positively correlated with the import scale of China on cotton.

3. The export price of the cotton of the importing country (region) of origin. The export price of cotton can reflect the supply capacity of the importing country (region) of origin. The higher the export price is, the lower its export capability is and the smaller the import volume of China is on cotton. Which raises assumption 3: the export price of the cotton of the importing country (region) of origin is negatively correlated with the import scale of China on cotton.

4. The geographical distance of the importing country (region) of origin with China. It is widely believed in the theoretical circle that the geographical distance is negatively correlated with the trade scale. As we know from H. Sandberg(2006) that the trade cost is positively correlated with the geographical distance, thus the trade cost is negatively correlated with the trade scale. Which raises assumption 4: the geographical distance of the importing country (region) of origin with China is negatively correlated with the import scale of China on cotton.

5. The population of China. The population of China reflects the import demand of China on cotton. The greater the population of China is, the higher its import potential is on import demand and more advantageous is to the cotton import of China. Which raises assumption 5: the population of China is positively correlated with the import scale of China on cotton.

6. The harvested area of cotton of China. The harvested area of cotton of China can reflect its supply capability on cotton. The larger the cotton harvested area is, the higher the self-supply capability of China and the smaller is on the volume of cotton import. Which raises assumption 6: the harvested area of cotton of China is negatively correlated with the import scale of China on cotton.

According to the above six elements, the gravity model of the improved trade of China on the import of cotton can be built up. This model can be represented by the following equation:

$$
\operatorname{Ln}\left(I M P_{j t}\right)=a_{1}+a_{2} \operatorname{Ln}\left(G D P_{i t}\right)+a_{3} \operatorname{Ln}\left(P_{j t}\right)+a_{4} \operatorname{Ln}\left(P_{j t}\right)+a_{5} \operatorname{Ln}\left(D_{I} S_{i j}\right)+a_{6} \operatorname{Ln}\left(P P_{i t}\right)+a_{7} \operatorname{Ln}\left(S_{i t}\right)+u
$$

Equation (1) is the improved gravity model of the cotton import of China, of which, $\mathrm{IMP}_{\mathrm{jt}}$ is the explained variable, expressed with the amount of cotton imported by our country from country (or region) $\mathrm{j}$ at the period of $\mathrm{t} ; \mathrm{PC}_{\mathrm{jt}}$ is the cotton yield of the importing country (region) $\mathrm{j}$ of origin at the period of $t$, which is used to measure the supply capacity of the country (or region) $\mathrm{j}$ of origin on cotton; $\mathrm{P}_{\mathrm{jt}}$ is the export price of cotton of the importing country (region) $\mathrm{j}$ of origin at the period of $\mathrm{t}$; DIS $_{\mathrm{ij}}$ is the geographical distance between our country and the importing country (region) of origin; POP $_{i t}$ is the population of our country at the period of $t ; S_{i t}$ is the harvested area of cotton of our country at the period of $t$. $a_{1}$ is a constant term, $a_{2}$ to $a_{7}$ are the regression coefficients and $u$ is an error term. 


\section{Analysis on the Trade Potential of China on Import of Cotton}

\section{Sample Selection and Data Sources}

As to accurately reflect the actual situation on the cotton import of China, we have chosen the 41 importing countries (regions) of origin of the largest amount of cotton import of China in 2016 for the sample analysis, including the United States, India, Australia, Uzbekistan, Brazil, Burkina Faso, Cameroon, Mali, Mexico, Benin, Cote d'Ivoire, Zimbabwe, Greece, Pakistan, Tanzania, Sultan, Zambia, Malaysia, Israel, Egypt, Turkey, Spain, Macau China, Mozambique, Togo, Malawi, Iran, Indonesia, Argentina, Senegal, Vietnam, Bangladesh, Turkmenistan, Nigeria, Tajikistan, Central African Republic, Philippines, Kazakhstan, Chad, Switzerland and Paraguay, which are all over in the North America, Oceania, Africa, Europe, Asia and South America. And besides, the total export amount of these trade partners to China in 2016 has reached USD 1,767 million, covering 99.6\% of the total import amount of cotton of our country. This is why we have chosen these 41 importing countries (regions) of origin to reflect the actual situation of our country on the import of cotton.

This paper will conduct a multiple linear regression analysis on the improved gravity model with Eviews 6.0 by referring to the penal data of our country and the trade partner countries (regions) from 1992 to 2016. The data sources are as follows: data of the variable IMP $_{\mathrm{jt}}$ is from UN COMTRADE database of the United Nations collected under SITC 3 standard; data of variable $\mathrm{P}_{\mathrm{jt}}$ is calculated on the basis of the import amount and import weight in the UN COMTRADE database of the United Nations; data of variables GDP ${ }_{\text {it }}$ and $\mathrm{POP}_{\text {it }}$ is from the database of www.worldbank.org.cn the World Bank; variable $\mathrm{PC}_{\mathrm{jt}}$ is from the database of the United Nations Food Agriculture Organization; and the data of variable DIS $\mathrm{ij}_{\mathrm{ij}}$ is from the latitude and longitude query system of http://www.hjqing.com/find/jingwei/; data of variable $S_{\text {it }}$ is from China Rural Statistical Yearbook of the past.

\section{Empirical Findings}

Based on the above research approach, we have conducted the multiple regression analysis on the equation (1) with the results received as follows in table 2.

We can see from table 2 clearly that the variable "the geographical distance between the importing country (or region) of origin and our country" has failed to pass the significance level test as $0.0915>0.05$. The most possible reason that caused this result is that the research samples include Macau, which belongs to China and is geographically close to Beijing. Thus we have excluded Macau in the second regression analysis and therefore there are a total of 40 trade partners in the second analysis samples. And then we conducted the analysis again on equation (1) and have received the results as the following table 3 .

Table 2 Statistical Regression Results of Equation (1)

\begin{tabular}{|c|c|c|c|c|}
\hline Variable & Coefficient & Standard Deviation & Value t & Value p \\
\hline $\mathrm{a}_{1}$ & 36.9227 & 0.0522 & 5.2339 & 0.0000 \\
\hline $\mathrm{Ln}\left(\mathrm{GDP}_{\mathrm{it}}\right)$ & 2.2306 & 0.0285 & 20.2304 & 0.0000 \\
\hline $\mathrm{Ln}\left(\mathrm{PC}_{\mathrm{jt}}\right)$ & 0.8926 & 0.0369 & 16.5216 & 0.0023 \\
\hline $\mathrm{Ln}\left(\mathrm{P}_{\mathrm{jt}}\right)$ & -1.0806 & 0.1032 & -11.6395 & 0.0000 \\
\hline $\mathrm{Ln}\left(\mathrm{DIS}_{\mathrm{ij}}\right)$ & -0.8325 & 0.1236 & -7.3254 & 0.0915 \\
\hline $\mathrm{Ln}\left(\mathrm{POP}_{\mathrm{it}}\right)$ & 0.8982 & 0.0426 & 6.4683 & 0.0081 \\
\hline $\mathrm{Ln}\left(\mathrm{S}_{\mathrm{it}}\right)$ & -2.0234 & 0.0937 & -9.5782 & 0.0000 \\
\hline
\end{tabular}


Table 3 Final Regression Results of Equation (1)

\begin{tabular}{|c|c|c|c|c|}
\hline Variable & Coefficient & Standard Deviation & Value t & Value p \\
\hline $\mathrm{a}_{1}$ & 25.3265 & 0.0433 & 6.3265 & 0.0000 \\
\hline $\mathrm{Ln}\left(\mathrm{GDP}_{\mathrm{it}}\right)$ & 2.4692 & 0.0196 & 21.6548 & 0.0001 \\
\hline $\mathrm{Ln}\left(\mathrm{PC}_{\mathrm{jt}}\right)$ & 1.5265 & 0.0505 & 18.3642 & 0.0013 \\
\hline $\mathrm{Ln}\left(\mathrm{P}_{\mathrm{jt}}\right)$ & -1.0659 & 0.0965 & -13.8993 & 0.0000 \\
\hline $\operatorname{Ln}\left(\mathrm{DIS}_{\mathrm{ij}}\right)$ & -0.8106 & 0.2088 & -5.6542 & 0.0083 \\
\hline $\operatorname{Ln}\left(\mathrm{POP}_{\mathrm{it}}\right)$ & 0.9441 & 0.0463 & 7.0549 & 0.0000 \\
\hline $\operatorname{Ln}\left(\mathrm{S}_{\mathrm{it}}\right)$ & -2.3624 & 0.0896 & -11.2369 & 0.0028 \\
\hline
\end{tabular}

The goodness-of-fit of the amended equation is quite good and the adjustment $\mathrm{R}^{2}$ of the regression equation is 0.905638 and value $\mathrm{F}$ is 98.38 . We can see from table 3 that the final results of the multiple regression analysis of equation (1) can be written to as follows:

$$
\begin{gathered}
\mathrm{Ln}\left(\mathrm{IMP}_{\mathrm{jt}}\right)=25.3265+2.4692 \mathrm{Ln}\left(\mathrm{GDP}_{\mathrm{it}}\right)+1.5265 \mathrm{Ln}\left(\mathrm{PC}_{\mathrm{jt}}\right)-1.0659 \mathrm{Ln}\left(\mathrm{P}_{\mathrm{jt}}\right)-0.8106 \mathrm{Ln}\left(\mathrm{DIS}_{\mathrm{ij}}\right)+0.9441 \mathrm{Ln} \\
\left(\mathrm{POP}_{\mathrm{it}}\right)-2.3624 \mathrm{Ln}\left(\mathrm{S}_{\mathrm{it}}\right)
\end{gathered}
$$

As to predict the import potential, the popular method is to compare the theoretical import value with the actual import value, and of which, the theoretical import value is from the calculation of the trade gravity model (i.e. equation 2).

The import potential index (IMPPI) of cotton of China can be received by dividing the theoretical value from equation (2) by the actual import value of cotton as follows:

$$
\mathrm{IMPPI}=\mathrm{IMP}_{\mathrm{j}} /\left(\mathrm{IMP}_{\mathrm{j}}\right)^{\prime}
$$

In the equation (3), $\mathrm{IMP}_{\mathrm{j}}$ represents the actual amount of cotton imported by China from country $\mathrm{j}$

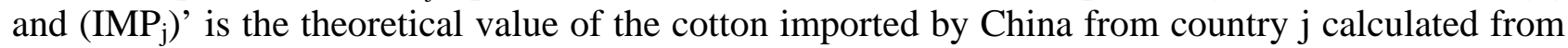
equation (2). According to the general standard of the theoretical circle, if the IMPPI of cotton of China from some importing countries (regions) of origin is larger than or equals to 1.3, then the cotton trade between China and these partners is faced with "excessive import" problem; and if it is larger than or equals to 0.9 but smaller than 1.3 , then the cotton trade is "saturated"; and if it is smaller than 0.9 , the trade is "insufficient".

According to Table 4 we can see that:

Table 4 Potential Index of China in importing cotton from 40 trading partners in 2016

\begin{tabular}{|c|c|c|c|c|c|c|}
\hline Country & Switzerland & Nigeria & Bangladesh & Indonesia & Turkey & Australian \\
\hline IMPPI & 7.05 & 6.76 & 6.38 & 6.12 & 5.69 & 4.21 \\
\hline Country & Mexico & Uzbekistan & Mozambique & Spain & Tanzania & Philippines \\
\hline IMPPI & 3.93 & 3.37 & 2.58 & 2.49 & 2.25 & 1.87 \\
\hline Country & Kazakhstan & Zimbabwe & Cameroon & Egypt & Togo & Chad \\
\hline IMPPI & 1.54 & 1.42 & 1.28 & 1.21 & 1.19 & 1.13 \\
\hline Country & Mali & India & Vietnam & America & Malawi & Sudan \\
\hline IMPPI & 1.10 & 1.06 & 1.04 & 1.03 & 0.98 & 0.95 \\
\hline Country & Pakistan & Ivory Coast & Zambia & Malaysia & Tajikistan & Brazil \\
\hline IMPPI & 0.93 & 0.88 & 0.87 & 0.84 & 0.83 & 0.79 \\
\hline Country & Israel & Greece & Turkmenistan & $\begin{array}{c}\text { Central } \\
\text { African } \\
\text { Republic }\end{array}$ & Benin & Paraguay \\
\hline IMPPI & 0.76 & 0.72 & 0.68 & 0.59 & 0.54 & 0.47 \\
\hline Country & Senegal & Argentina & Iran & Burkina Faso & & \\
\hline IMPPI & 0.45 & 0.38 & 0.36 & 0.34 & & \\
\hline
\end{tabular}


(1) There're 14 countries that belongs to the excessive cotton import countries of China, including Switzerland, Nigeria, Bangladesh, Indonesia, Turkey, Australia, Mexico, Uzbekistan, Spain, Tanzania, Mozambique, the Philippines, Kazakhstan, and Zimbabwe, with the potential index of China in importing cotton over 1.3. The cotton imported by China from these countries are oversaturated. Among these countries, Switzerland, Nigeria, Bangladesh, Indonesia, Turkmenistan, Australia, Mexico and Uzbekistan have the maximum market saturation, with the potential index of China in importing cotton over 3. It shows that China has a very small space to continue expanding cotton imports from these trading partners. In particular, Australia is the world's third largest exporter of cotton in 2016, with $70.04 \%$ of the total cotton export undertaken by China.

(2) There're 11 countries that belongs to the saturated cotton import countries of China, including Cameroon, Egypt, Togo, Chad, Mali, India, Vietnam, the United States, Malawi, Sudan and Pakistan, with the potential index of China in importing cotton no less than 0.9 but less than 1.3. It shows that China has limited space to expand cotton imports from these trading partners. Taking the United States and India as examples, they're the world's largest and second largest cotton exporters in 2016, with $42.71 \%$ and $49.76 \%$ of the total cotton export undertaken by China respectively.

(3) There're 15 countries that belongs to the cotton under-imported countries of China, including ivory coast, Tajikistan, Zambia, Malaysia, Brazil, central African republic, Israel, Greece, Turkmenistan, Senegal, Benin, Paraguay, Argentina, Iran and Burkina Faso, with the potential index of China in importing cotton below 0.9. It shows that China has large space to expand cotton imports from these trading partners, and China should focus on developing these emerging markets.

\section{Policy Suggestion}

(1)China should create fair and transparent conditions and encourage enterprises to participate in the cotton trade. In the future, the growth space of cotton in China will be limited, and the large number of textile garments will remain unchanged in the short term, so the import of cotton will still be the reality that the domestic cotton industry must face. The import of cotton should be a useful supplement to the domestic cotton market, which is also conducive to the creation of more social wealth. However, no more cotton import quotes was released except for a 894000 tons that China promised by China to the WTO since 2015, which requires China to adopt relevant policies to ensure the fair and transparent allocation of cotton import quotas so as to avoid corruption such as rent-seeking. In addition, China should actively encourage domestic cotton enterprises to participate in the international trade of cotton in order to achieve the maximum profit.

(2)Among the major cotton importing partner of China, the potential of Australia, the United States, India and Uzbekistan has already been well developed, and these countries belong to the categoty of excessive import or saturated import countries. The excessive concentration of cotton import market is not conductive to the trade safety of cotton import in China. Therefore, China urgently needs to expand other markets besides these relatively stable suppliers to avoid further concentration of the cotton import market.

(3)Turkmenistan, Iran and Malaysia provided very preferential price, being USD 0.78/kg, USD $1.01 / \mathrm{kg}$ and USD $1.05 / \mathrm{kg}$ respectively in 2016. Therefore, China can prioritize the import of these markets to reduce the cost, thereby reducing the cost of raw materials for domestic textile and clothing products. In addition, Brazil and Greece, which ranked fifth and seventh in cotton exports in 2016, are also countries with "insufficient imports" of Chinese, accounting for $29.31 \%$ and $11.48 \%$ respectively, and the cotton exporting price of these two countries were in the upper and middle levels, about USD 2/kg, so China can increase the share of cotton imported from these two countries. Besides, China should assist the importing cotton enterprises to join together and form the monopoly power of the buyer through joint negotiations, thus to enhance the bargaining power of our enterprises in the import trade of cotton.

\section{Acknowledgement}

Thanks for the help from the Project of Zhejiang philosophy and social science planning "Study on Benefit Prediction and Promoting path of Zhejiang Agricultural Machine’s Substitution of Man” (No. 
18NDJC009Z). Thanks to Zhejiang College Students’ Technology \& Innovation Program namely Zhejiang XinMiao Program named “On Zhejiang Agricultural Machine’s Substitution of Man based on the Country Strategy”.

\section{References}

[1]BERGSTRAND JH, The Gravity Equation in International Trade: Some Microeconomic Foundations and Empirical Evidence. Review of Economics and Statistics, 1985(67):89 102

[2]Carrère Céline.Revisiting the effect of regional trade agreements on trade flows with proper specification of the gravity model. European economic review, 2006(5):223 247

[3]Nuroglu E, Dreca N. Analyzing Bilateral Trade Flows of Bosnia and Herzegovina under the Framework of Gravity Model. Journal of Business \& Economics, 2011(1):30 50

[4]Jin Zhesong. The Structure and Flow of International Trade. Beijing: China Planning Press,2000 (in Chinese)

[5]Wang Xiaoshan. Study on Influence Factors of Inbound Tourism in China based on Gravity Model. Mater Dissertation Research Paper of University of Hainan, 2014 (in Chinese)

[6]Zhang Huafeng. Analysis of International Competitiveness and Influencing Factors of China's Cotton Industry [D]. Mater Dissertation Research Paper of Shandong Agricultural University,2016 (in Chinese) 